

Global JOURnAl of MEdicAl ReseARCH: F

DISEASES

Volume 21 Issue 8 Version 1.0 Year 2021

Type: Double Blind Peer Reviewed International Research Journal

Publisher: Global Journals

Online ISSN: 2249-4618 \& Print ISSN: 0975-5888

\title{
Pulmonary Function Tests in Patients with Chronic Rhinosinusitis: A Comparative Study
}

By Prof Dr. Ramesh Azad, Dr. Siddharth Sharma \& Dr. Sunil Sharma

Abstract- Coexistence of upper and lower respiratory diseases has long been known. Since chronic rhinosinusitis and pulmonary diseases are closely related this study was made to observe the pulmonary function of patients with chronic rhinosinusitis.

Methods: The study was conducted in the Department of ENT and Pulmonary Medicine, IGMC Shimla on 27 adult patients of chronic rhinosinusitis and 26 age matched healthy control subjects between November 2018 and November 2019. The pulmonary function tests were performed using a spirometry and included Vital Capacity (VC), Forced vital capacity (FVC), Forced expiratory volume in one second (FEV1) and Forced expiratory volume in one second by Forced vital capacity ratio (FEV1/FVC).

Results: Following observations were made from the results of the study, among controls majority of the subjects i.e 23 (92\%) had a normal PFT with only 1 patient (4\%) had mild and another 1 patient (4\%) had moderate restriction on PFT. Whereas among the patients group 10 patients (37\%) had a normal pre-operative baseline PFT. Another $10(37 \%)$ and 7 patients (25.9\%) had mild and moderate obstruction respectively.

Keywords: chronic rhinosinusitis, unified airway, PFT, lung function.

GJMR-F Classification: NLMC Code: WG 269

$\|1\||N|$

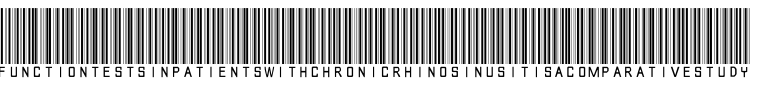

Strictly as per the compliance and regulations of:

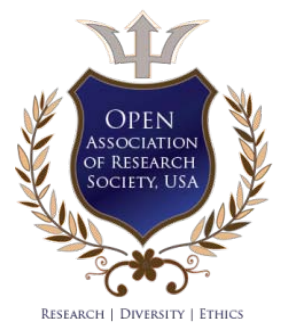

(c) 2021. Prof Dr. Ramesh Azad, Dr. Siddharth Sharma \& Dr. Sunil Sharma. This research/review article is distributed under the terms of the Attribution-NonCommercial-NoDerivatives 4.0 International (CC BY-NC-ND 4.0). You must give appropriate credit to authors and reference this article if parts of the article are reproduced in any manner. Applicable licensing terms are at https://creativecommons.org/licenses/by-nc-nd/4.0/. 


\title{
Pulmonary Function Tests in Patients with Chronic Rhinosinusitis: A Comparative Study
}

\author{
Prof Dr. Ramesh Azad ${ }^{\alpha}$, Dr. Siddharth Sharma ${ }^{\sigma} \&$ Dr. Sunil Sharma ${ }^{\rho}$
}

Abstract- Coexistence of upper and lower respiratory diseases has long been known. Since chronic rhinosinusitis and pulmonary diseases are closely related this study was made to observe the pulmonary function of patients with chronic rhinosinusitis.

Methods: The study was conducted in the Department of ENT and Pulmonary Medicine, IGMC Shimla on 27 adult patients of chronic rhinosinusitis and 26 age matched healthy control subjects between November 2018 and November 2019. The pulmonary function tests were performed using a spirometry and included Vital Capacity (VC), Forced vital capacity (FVC), Forced expiratory volume in one second (FEV1) and Forced expiratory volume in one second by Forced vital capacity ratio (FEV1/FVC).

Results: Following observations were made from the results of the study, among controls majority of the subjects i.e 23 (92\%) had a normal PFT with only 1 patient $(4 \%)$ had mild and another 1 patient (4\%) had moderate restriction on PFT. Whereas among the patients group 10 patients (37\%) had a normal pre-operative baseline PFT. Another 10 (37\%) and 7 patients $(25.9 \%)$ had mild and moderate obstruction respectively.

Conclusion: Findings of the current study suggest that their are latent derangements in the pulmonary functions of patients with upper airway disease ie chronic rhinosinusitis and the difference between the pulmonary functions of patients and controls is significant. Hence our study validates the Unified airway disease model and suggests that lower airway evaluation shall be done in patients with chronic upper airway disease and a timely diagnosis and intervention could be beneficial for the pulmonary diseases.

Keywords: chronic rhinosinusitis, unified airway, PFT, lung function.

\section{INTRODUCTION}

$\sim$ hronic rhinosinusitis (CRS) is an inflammatory disease of the mucosa of the nasal cavity and paranasal sinuses, with symptoms lasting 12 weeks or more. It is a common disease and represents a public health problem resulting in socioeconomic burden throughout the world[1]. The exact pathogenesis of CRS is still not clearly understood; it significantly affects quality-of-life measures with decrements in general health perception and social functioning. It has been long recognized that diseases coexist in the upper and lower airways. The "United-Airways" concept implies that there is a link between upper and lower airway inflammation[2].

Author: e-mail: sid.sidpion06@gmail.com
Galenus was the first to note an association of nasal symptoms and asthma in the 2nd century he defined the nose as a respiratory instrument in his work "De usupartium". From the literature, it appears that Kariya et al[3] were the first to report the latent obstruction in low diameter airways associated with CRS. Their suggestion was that obstructive pulmonary alterations were present in CRS cases, even where they caused no symptoms and had not led to a diagnosis of obstructive airway disease. Chien et al[4] reported that chronic obstructive pulmonary disease was associated with an increased risk of Chronic rhinosinusitis without nasal polyps, independent of a number of potential confounding factors. Both the upper and lower respiratory tracts are continually exposed to gases and airborne particles. The importance of host defence mechanisms is vital. Physical barriers, mucociliary clearance systems with immune processes combine to protect the lung from damage. When abnormalities of these mechanisms occur, the patient may first present to the otolaryngologist before serious bronchopulmonary involvement occurs. The mechanisms that connect upper and lower airway dysfunction are under investigation. They include a nasal-bronchial reflex, mouth breathing caused by nasal obstruction, and pulmonary aspiration of nasal contents and a direct evidence of an association could be obtained by examining the objective results of pulmonary function tests of patients with CRS and comparing them with results of healthy controls.

\section{il. Methods and Materials}

The study was conducted in the Departments of Otorhinolaryngology and Pulmonary medicine, Indra Gandhi Medical College, Shimla, Himachal Pradesh between November 2018 and November 2019.

a) Study type

A hospital based study.

b) Study Design

A comparative observational study.

C) Subjects and Sample size

The study included 52 participants with 27 patients fulfilling the clinical criteria for CRS and 25 age matched healthy controls. The subjects in both groups belonged to the age group 18-60 years. 


\section{d) Inclusion Criteria}

Patients suffering from CRS as documented by history, clinical examination and radiological investigations were included in the patients group. Symptoms and findings of CRS were based on the CRS criteria and divided into major and minor factors as established by the American Academy of Otolaryngology and Head and Neck Surgery in 1996. These parameters have since become widely adopted by researchers and by health maintenance organizations CRS diagnosis requires presence of at least 2 major factors or one major factor with 2 or more minor factors, or nasal purulence on examination.

e) Exclusion Criteria

- Pregnant women

Coexistent systemic diseases like diabetes, hypertension, neoplasia.

- Patients with known psychiatric illness.

- Prior paranasal sinus, nose or throat surgery.

f) Controls

The study participants belonging to the same age group as patients group who presented to ENT OPD after ruling out CRS and the exclusion criteria by means of clinical examination and were taken as controls.

\section{g) Pulmonary Function Tests}

PFT were assessed using Spirometer, Vitalograph model number 6800. Spirometry is a powerful tool that can be used to detect, follow, and manage patients with lung disorders. It is reliable and relatively simple to incorporate into a routine office visit. To determine the validity of spirometric results, a Minimum of 3 acceptable maneuversviz: FEV1 and FVC maneuver, VC and IC maneuver and Peak exploratory flow were done as per criteria laid down by latest ATS (American thoracic society) guidelines. In each test, patients exhaled for at least six seconds and stopped when there was no volume change for one second. The test session was finished when the difference between the two largest FVC measurements and between the two largest FEV1 measurements was found to be within 0.2 L.

Results of spirometery were graded as per Gold 2017 standards[5]. The PFT values were considered to indicate significant airway obstruction when FEV1/FVC $<0.7$ and FEV1 $<80 \%$ of the predicted value for a patient's age, height and weight.

\section{h) Statistical analysis}

Data is presented as frequency, percentages, and maximum minimum and mean \pm SD wherever applicable. Data is also depicted in tables and bar graphs wherever possible. Proportions are compared by Chi square as appropriate to the data set. Means are compared by student $t$ test and a $P$ value of $<0.05$ is considered to be statistically significant.

\section{Results}

A total of 52 adult subjects including 27 CRS patients and 25 healthy controls who presented to ENT OPD after thorough clinical history and physical examination were enrolled for the study after matching them with our inclusion and exclusion criteria.

\section{a) Age distribution of participants}

The age of participants included in patient group ranged from 18 to 60 years with a mean of 40.59 \pm 13.49 years. The maximum number of patients (15) belonged to $41-60$ age group representing $55.6 \%$ of total, in control group age ranged from 30 to 60 years with a mean of $48.68 \pm 11.32$ years with maximum participants in $41-60$ years representing $72 \%$ of the total. The data is depicted in Table 1.

Table 1: Age wise distribution of study group and control group

\begin{tabular}{|c|c|c|c|c|c|c|}
\hline \multirow{2}{*}{ Age (in years) } & \multicolumn{2}{|c|}{ Study group } & \multicolumn{2}{c|}{ Controls } & \multirow{2}{*}{$\begin{array}{c}\text { Chi-square } \\
\text { value }\end{array}$} & P value \\
\cline { 2 - 5 } & Frequency & Percentages & Frequency & Percentages & \multicolumn{2}{|c}{} \\
\hline$\leq 20$ & 2 & 7.4 & 0 & 0.0 & \multirow{2}{*}{3.201} & \\
\hline $21-30$ & 6 & 22.2 & 3 & 12.0 & \\
\hline $31-40$ & 4 & 14.8 & 4 & 16.0 & \\
\hline $41-60$ & 15 & 55.6 & 18 & 72.0 & & \\
\hline Total & 27 & 100.0 & 25 & 100.0 & & \\
\hline
\end{tabular}

Statistical Analysis: Chi-square test. $P \leq 0.05$ : Statistically significant (S)

b) Demographic profile of participants

The weight of patients in the study group ranged from $35 \mathrm{~kg}$ to $82 \mathrm{~kg}$ with a mean of $61.56 \pm 13.45$ $\mathrm{kgs}$. The height of the patients in study group ranged from $145 \mathrm{~cm}$ to $185 \mathrm{~cm}$ with a mean of $165.07 \pm$ $10.38 \mathrm{~cm}$. The BMl ranged from 15 to 28.50 with a mean of $22.69 \pm 3.53$. In the control group weight ranged from $35 \mathrm{~kg}$ to $79 \mathrm{~kg}$ with a mean of $60.12 \pm 11.37 \mathrm{~kg}$. Height ranged from $105 \mathrm{~cm}$ to $180 \mathrm{~cm}$ with a mean of $160.16 \pm$ 15.35. Mean BMl among control group was $22.60 \pm$ 3.50. The demographic data is represented in Table 2. 
Table 2: Demography of participants

\begin{tabular}{|c|c|c|c|c|c|c|c|c|}
\hline Statistics & $\begin{array}{c}\text { Age } \\
\text { (control) }\end{array}$ & $\begin{array}{c}\text { Age } \\
\text { (Patients) }\end{array}$ & $\begin{array}{c}\text { Weight } \\
\text { (Controls) }\end{array}$ & $\begin{array}{c}\text { Weight } \\
\text { (Patients) }\end{array}$ & $\begin{array}{c}\text { Height } \\
\text { (Controls) }\end{array}$ & $\begin{array}{c}\text { Height } \\
\text { (Patients) }\end{array}$ & $\begin{array}{c}\text { BMI } \\
\text { (Controls) }\end{array}$ & $\begin{array}{c}\text { BMl } \\
\text { (Patients) }\end{array}$ \\
\hline Minimum & 30 & 18.00 & 35.00 & 35.00 & 105.00 & 145.00 & 14.50 & 15.00 \\
\hline Maximum & 60 & 60.00 & 79.00 & 82.00 & 180.00 & 185.00 & 29.30 & 28.50 \\
\hline Mean & 48.68 & 40.59 & 60.12 & 61.56 & 160.16 & 165.07 & 22.60 & 22.69 \\
\hline Median & 50.00 & 41.00 & 60.00 & 60.00 & 160.00 & 165.00 & 22.80 & 24.00 \\
\hline Std. deviation & 11.32 & 13.41 & 11.37 & 13.45 & 15.35 & 10.38 & 3.50 & 3.53 \\
\hline $\begin{array}{c}\text { Std. Error of } \\
\text { mean }\end{array}$ & 2.26 & 2.58 & 2.27 & 2.59 & 3.07 & 2.00 & 0.70 & 0.68 \\
\hline
\end{tabular}

c) PFT Values in controls

Majority of patients (23) in control group had a normal pulmonary function accounting for $92 \%$ of total whereas one patient each had mild and moderate restriction in pulmonary function test. Mean Vital capacity among controls was $82.80 \%$ of predicted. The mean FVC was $90.08 \%$ of predicted value. $\mathrm{FEV}_{1}$ mean was $72.89 \%$ of the predicted value. FEV 1 /FVC ratio had a mean $97.12 \%$ of the predicted value. The data is represented in Table 3.

Table 3: Pulmonary function in Control group

\begin{tabular}{|c|c|c|c|c|c|c|c|c|}
\hline Statistics & $\begin{array}{l}\text { VC/ Vital } \\
\text { capacity }\end{array}$ & $\begin{array}{c}\text { VC/ Vital } \\
\text { capacity } \\
\%^{*}\end{array}$ & $\mathrm{FVC}(\mathrm{L})$ & FVC\% & FEV1(L) & FEV1\% & FEV1/FVC & FEV1/FVC\% \\
\hline Minimum & 1.85 & 60.00 & 1.99 & 72.00 & 1.58 & 50.00 & 1.07 & 70.00 \\
\hline Maximum & 3.82 & 114.00 & 4.19 & 119.00 & 3.48 & 117.00 & 1.43 & 112.00 \\
\hline Mean & 3.07 & 82.80 & 3.23 & 90.08 & 2.63 & 84.80 & 1.28 & 97.12 \\
\hline Median & 3.33 & 83.00 & 3.36 & 88.00 & 2.68 & 84.00 & 1.29 & 100.00 \\
\hline $\begin{array}{c}\text { Std. } \\
\text { deviation }\end{array}$ & 0.57 & 13.15 & 0.61 & 11.65 & 0.46 & 14.72 & 0.08 & 10.16 \\
\hline SE of mean & 0.11 & 2.63 & 0.12 & 2.33 & 0.09 & 2.94 & 0.02 & 2.03 \\
\hline
\end{tabular}

d) PFT in patients group

Among patients group of 27, 10 (37\%) had a normal pre-operative baseline PFT. Another 10 (37\%) and 7(25.9) had mild and moderate obstruction. Mean Vital capacity of the patients was $74.59 \%$ of predicted.
The mean FVC was $81.15 \%$ of predicted value. FEV mean was $72.89 \%$ of the predicted value. $\mathrm{FEV}_{1} / \mathrm{FVC}$ ratio had a mean $90.16 \%$ of the predicted value for patients. The data is represented in table 4.

Table 4: Pulmonary function in patients group

\begin{tabular}{|c|c|c|c|c|c|c|c|l|}
\hline \multirow{2}{*}{ Statistics } & \multicolumn{2}{|c|}{} & & & & & & \\
\cline { 2 - 9 } & $\mathrm{VC}(\mathrm{L})$ & $\mathrm{VC} \%{ }^{*}$ & $\mathrm{FVC}(\mathrm{L})$ & $\mathrm{FVC} \%$ & $\mathrm{FEV}_{1}(\mathrm{~L})$ & $\mathrm{FEV}_{1} \%$ & $\mathrm{FEV}_{1} / \mathrm{FVC}$ & $\mathrm{FEV}_{1} / \mathrm{FVC}$ \\
\hline Minimum & 1.29 & 46.00 & 1.12 & 41.00 & 0.77 & 33.00 & 0.35 & 43.00 \\
\hline Maximum & 3.96 & 97.00 & 5.00 & 112 & 3.57 & 105.00 & 0.95 & 115.00 \\
\hline Mean & 2.60 & 74.59 & 2.75 & 81.15 & 2.08 & 72.89 & 0.73 & 90.19 \\
\hline Median & 2.53 & 73.00 & 2.68 & 81.00 & 2.03 & 76.00 & 0.75 & 96.00 \\
\hline Std.deviation & 0.80 & 14.41 & 0.90 & 18.21 & 0.70 & 19.01 & 0.14 & 18.38 \\
\hline S.E of mean & 0.15 & 2.77 & 0.17 & 3.50 & 0.13 & 3.66 & 0.03 & 3.54 \\
\hline
\end{tabular}

Our study observed that among controls out of 25 majority of the subjects i.e 23 (92\%) had a normal PFT with only 1 patient (4\%) had mild and another 1 patient had moderate restriction on PFT. Whereas among the patients group out a total of 27, 10 (37\%) had a normal pre-operative baseline PFT. Another 10
(37\%) and 7(25.9) had mild and moderate obstruction respectively.

The mean difference between the $\mathrm{VC}$ of controls and patients was 0.47 Litres with a $p$ value of 0.018 . The mean difference between the FVC of controls and patients was 0.48 litres with a p- value of 0.030 . The 
mean difference between the FEV1 of controls and FEV1 of patients was 0.55 Litres with a p-value of 0.002 . The mean difference between the FEV1 / FVC ratio of controls and patients was 0.55 with a p-value of 0.001 .

Thus our study found a statistically significant differences between the PFT of the controls and patients with CRS among all the parameters studied.

\section{Discussion}

Respiratory tract infections are quite commonly managed by health care providers. A recent report from the Centers for Disease Control, respiratory infections (upper respiratory tract infections, otitis media, and lower respiratory tract infections) accounted for $16 \%$ of all outpatient visits of patients to physicians [6]. The nose functions as the air conditioner of human body delivering inspired air to the tracheobronchial tree which comes into contact with large surface area of the nasal mucosa permitting three physiological functions of: filtration, warming and humidification[7]. Inhalation of warm, moist air into the lower airway is required for the optimal functioning of the bronchopulmonary system hence chronic nasal dysfunction can contribute significantly to lower respiratory diseases such as asthma and chronic bronchitis.

The present study is an observational and comparative study including a total of 52 subjects with 25 healthy controls and 27 patients of CRS whose pulmonary function tests were evaluated with the objective to evaluate and compare the pulmonary function among the two groups. There have been quite a few studies demonstrating association of upper airway diseases with asthma and other lower airway conditions in past[8] but to the best of our knowledge this is one of the first study done in the Himalayan state of Himachal Pradesh to study the association of lower airway involvement in CRS.

Out of 27 CRS patients maximum number of patients $n=27(55.6 \%)$ belonged to the age group of 41-60 years with mean age of 40.59 years. Similarly Sokol in a 2000 study[9] evaluated 16,000 patients suffering from CRS and found the mean age of patients comparable i.e 44 years.

In our present study majority of patients were male with $\mathrm{n}=17$ (63\%) whereas females constituting $37 \%$ with $n=10$. With a male to female ratio of $1.7: 1$. This is in accordance with a similar study done by Ahmed M Youssef[10] in 2017 on 25 patients with CRS in which male constituted a majority $60 \%(n=15)$. Another Indian study conducted by Ziauddin Ahmed[11] in 2017 found a male preponderance 32 out of a total of 48 with males constituting $66.6 \%$ of the total cases.

\section{a) Pulmonary function tests}

Our study found that CRS patients had significantly poorer pulmonary functions compared to healthy controls. Similarly results of a 2004 study by
Ragab A et al[12] showed that $60 \%$ of patients with CRS had different kinds of lower airway involvement. Some are manifest such as asthma and some are hidden such as small airway disease and bronchial hyper-reactivity.

Our study found significant differences in pulmonary functions of healthy controls and the patients suffering from CRS. A total of 17 patients (63.9\%) out of 27 having degranged pulmonary functions. with $n=10$ (37\%) of patients having mild pulmonary obstruction and $\mathrm{n}=7$ (25.9\%) of patients having moderate pulmonary obstruction. Whereas compared to control group where only 2 patients ( $8 \%$ ) out of a total of 25 had deranged pulmonary function test with $n=1$ patient (4\%) having mild and $n=1(4 \%)$ having moderate obstruction. The mean vital capacity in patients group was 2.60 litres $(74.59 \%)$ as compared to the mean vital capacity in the control group which was 3.07 I (82.80\%). This difference was statistically significant with a $p$ value of 0.018 . The mean FVC in patients group was 2.75 litres (81.15\%) whereas in controls it was 3.23 litres (90.08\%) this difference was also statistically significant with a $p$ value of 0.03 . The mean $\mathrm{FEV}_{1}$ in patients group was 2.08 litres (72.89\%) whereas in control group the mean $\mathrm{FEV}_{1}$ was $2.63(84.80 \%)$ the difference between patients and controls was highly significant statistically with a $p$ value of 0.02 . The mean $\mathrm{FEV}_{1} / \mathrm{FVC}$ ratio in the patients group was $0.73(90.19 \%)$ as compared to control group which had a mean of 1.28(97.12\%). Table 11,12,13,14. Findings of our present study matched the findings of a study done by Kariya $S$ et al[13] in 2014 to evaluate the pulmonary function of 273 patients with CRS and 100 age-matched normal control subjects .CRS patients had significant obstructive lung function changes regardless of the presence of asthma. Similar results were observed in a retrospective study done on 284 subjects by Suh Young Lee et al[14] in 2010 to evaluate the influence of chronic sinusitis and nasal polyp on the lower airway of subjects without lower airway diseases. This study provided evidence that the presence of CT findings suggestive of chronic sinusitis is associated with a subclinical airflow limitation in subjects without lower respiratory disease. A unified airway disease hypothesis[15] may be valid for subjects even without definite lung disease.

The results of our study showed that majority of the patients had derranged pulmonary functions even if they had not been diagnosed with an overt lower airway disease these results are in accordance with the results of a study done by GottliebMJ[16] in a 1925 on 117 cases of asthma, found that in all there were 31 cases of disease in one or more of the paranasal sinuses, a correlation was found between lower airway and upper airway diseases.

This nonsymptomatic lower airway involvement in patients with CRS can be explained by the small lower airway dysfunction that involves the terminal and respiratory bronchioles. Another entity of lower airway 
functional involvement is the inflammation of the lower airways resulting in bronchial hyperreactivity[17][18]. Nasal obstruction can induce a blockage of the sinus ostia, with a reduction in the availability of nitric oxide in the upper and lower airways, as reported for patients with chronic sinus disease[19].

\section{Conclusion}

Coexistence of upper and lower respiratory diseases is common. Our study found a significant derangement in the pulmonary functions of patients with CRS not previously diagnosed with any lower airway diseases. A united airway disease hypothesis may thus be valid. How exactly the upper airway disease effects lower airway is still a matter a of debate and beyond the scope of present study. However several hypotheses exist, like nasopharyngo bronchial reflexes that may lead to airway hyper responsiveness. Also sinonasal mucosal inflammation may lead to pulmonary inflammation by releasing chemotactic factors and leukocytes. Oral breathing caused by CRS may also lead to inhalation of cold dry air and environmental pollutions bypassing the protective nasal function. Although our study is limited by a relatively small number of patients with most of the patients having the disease since many months if not years, our comparative study, with its well-defined outcome and criteria included for patient selection, helps to clarify the true value of lower airway assessment in these difficult-to-treat patients and to emphasize that the underuse of objective testing, such as spirometry for patients with CRS may lead to underdiagnosed lower airway problems.

\section{Demographics of participants}

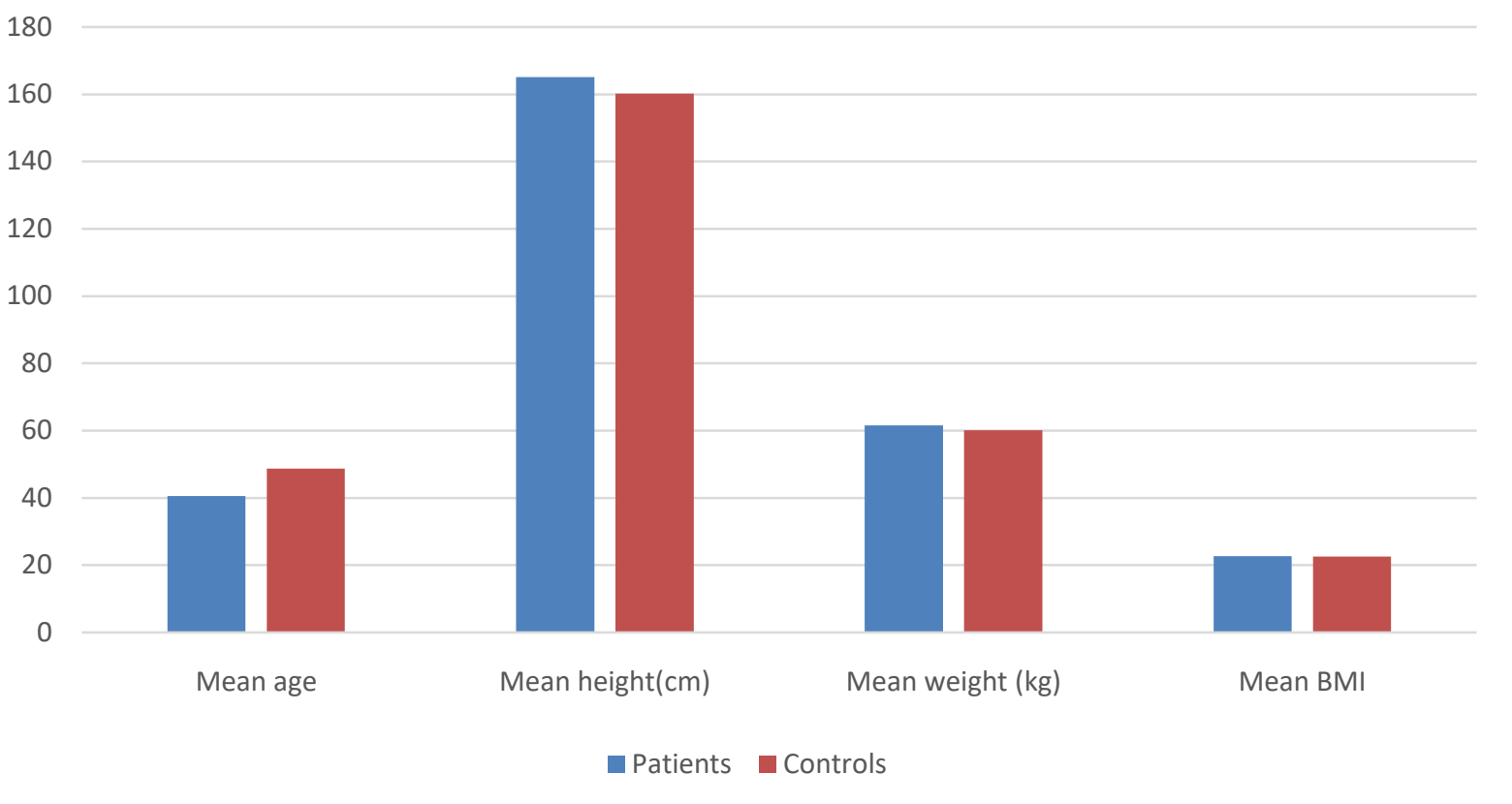

Figure 1: Demographic data of participants 


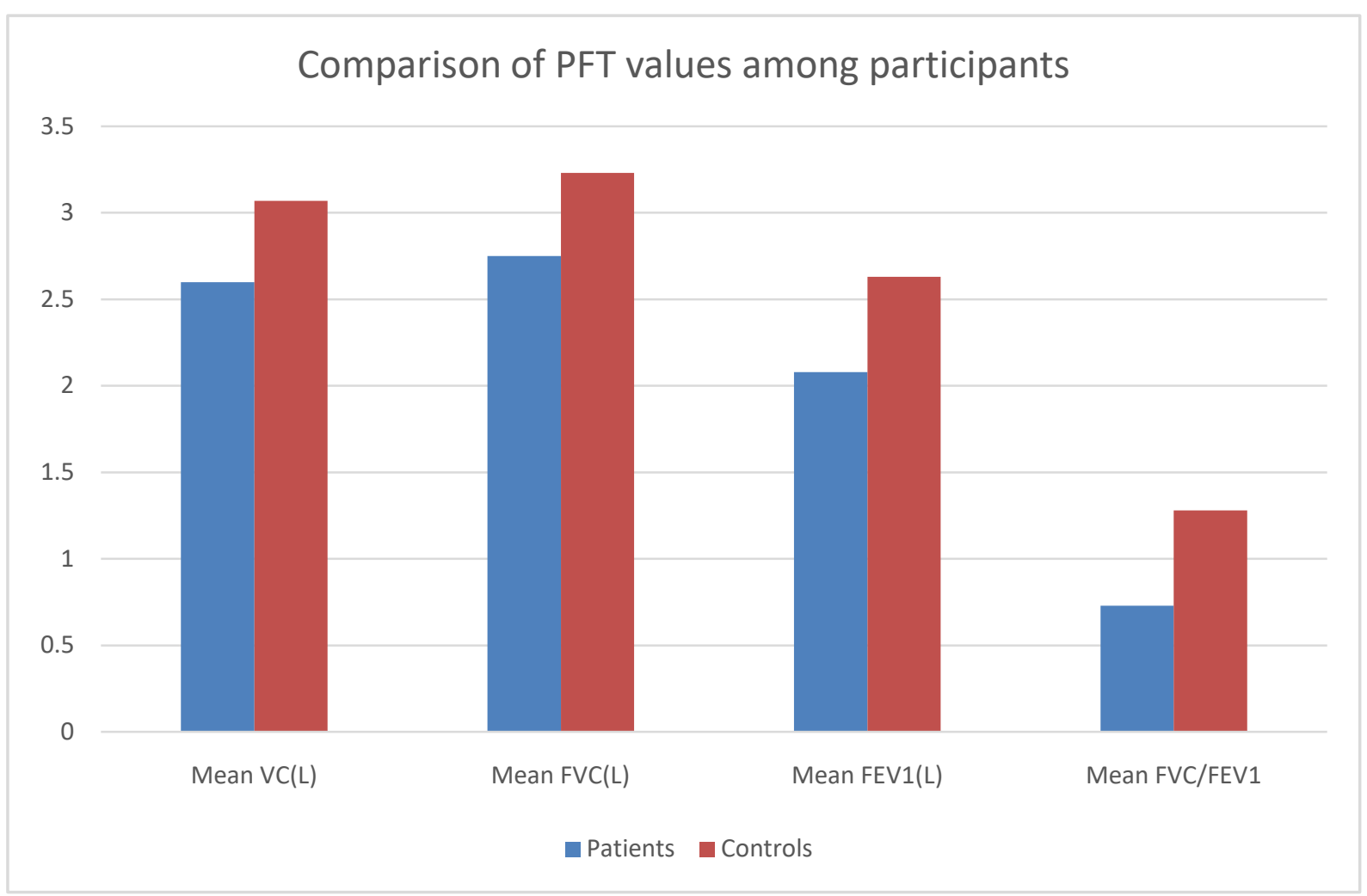

Figure 2: PFT comparison between patients and controls

\section{BIBLIOGRAPHY}

1. International Rhinosinusitis Advisory Board. Infectious rhinosinusitis in adults: classification, etiology and management. Ear Nose Throat $\rfloor$ 1997; 76:1-22.

2. Bachert C, Vignola AM, Gevaert P, Leynaert B, Cauwenberge PV, Bousquet J. Allergic rhinitis, rhinosinusitis, and asthma: one airway disease. Immunology and Allergy Clinics of North America. 2004; 24(1): 19-43.

3. Kariya $S$, Okano $M$, Oto $T$, Higaki $T$, Makihara $S$, Haruna $T$, et al. Pulmonary function in patients with chronic rhinosinusitis and allergic rhinitis. The Journal of Laryngology \& Otology. 2014; 128(3): 255-62.

4. Chien C-Y, Tai S-Y, Wang L-F, Lee CT-C. Chronic Obstructive Pulmonary Disease Predicts Chronic Rhinosinusitis without Nasal Polyps: A PopulationBased Study. American Journal of Rhinology \& Allergy. 2015; 29(3).

5. Vogelmeier C, Criner G, Martinez F, Anzueto A, Barnes $P$, Bourbeau $J$ et al. Global Strategy for the Diagnosis, Management, and Prevention of Chronic Obstructive Lung Disease 2017 Report. GOLD Executive Summary. American Journal of Respiratory and Critical Care Medicine. 2017; 195(5): 557-582.

6. Armstrong GL, Pinner RW. Outpatient Visits for Infectious Diseases in the United States, 1980
Through 1996. Archives of Internal Medicine. 1999; 159(21): 2531.

7. Borum P. Functional Anatomy and Physiology of the Nose. Ear, Nose \& Throat Journal. 1992; 71(1):8-10.

8. Bullen SS. Incidence of asthma in 400 cases of chronic sinusitis. Journal of Allergy. 1933; 4(5): 402-7.

9. Sokol W. Epidemiology of sinusitis in the primary care setting: results from the 1999-2000 respiratory surveillance program. The American Journal of Medicine. 2001;111(9):1

10. Youssef AM, Awad OGA-N, Taha M. Pulmonary Function of Patients with Chronic Rhinosinusitis and the Impact of Endoscopic Sinus Surgery. OTO Open. 2017; 1(4).

11. Ahmad Z. The Effect of Functional Endoscopic Sinus Surgery on Pulmonary Functions of Patients with Pulmonary Diseases and Sinusitis. Ann. Int. Med. Den. Res. 2018; 4(6): EN05-EN09.

12. Ragab A, Clement P, Vincken W. Objective Assessment of Lower Airway Involvement in Chronic Rhinosinusitis. American Journal of Rhinology. 2004; 18(1): 1

13. Kariya S, Okano M, Higaki T, Noyama $Y$, Haruna $T$, Ishihara $\mathrm{H}$ et al. Chronic rhinosinusitis patients have decreased lung function. International Forum of Allergy \& Rhinology. 2014; 4(10): 828-833.

14. Lee S, Yoon S, Song W, Lee S, Kang H, Kim S et al. Influence of Chronic Sinusitis and Nasal Polyp on the Lower Airway of Subjects Without Lower Airway 
Diseases. Allergy, Asthma \& Immunology Research. 2014; 6(4): 31.

15. Passalacqua G. United airways disease: therapeutic aspects. Thorax. 2000Jan; 55(90002).

16. Gottlieb MJ. Relation of Intranasal Disease in the Production of Bronchial Asthma. Journal of the American Medical Association. 1925Nov; 85(2):105.

17. Hurst JR, Wilkinson TMA, Perera WR, Donaldson GC, Wedzicha JA. Relationships among Bacteria, Upper Airway, Lower Airway, and Systemic Inflammation in COPD. Chest. 2005; 127(4): 1219-26.

18. Karuthedath S, Singh I, Chadha S. Impact of Functional Endoscopic Sinus Surgery on the Pulmonary Function of Patients with Chronic Rhinosinusitis: A Prospective Study. Indian Journal of Otolaryngology and Head \& Neck Surgery. 2014Aug; 66(4): 441-8.

19. Frendø, M, Håkansson, K, Schwer, S. Asthma in ear, nose, and throat primary care patients with chronic rhinosinusitis with nasal polyps. Am J Rhinol Allergy. 2016; 30: 67-71. 